\title{
Effective Psychological Treatment in Case of Car Accident
}

\author{
Victoria Dunaeva \\ The co-founder and head of Activus Aspectus. Innovative Laboratory
}

\begin{abstract}
.
Psychological trauma caused by participation in car accident is often ignored when a person wasn't physically injured. Being in the shock after a car accident a person may not realize what he/she emotionally experienced.

However, in my practice of clinical psychologist I observe that my clients who provoked car accident feel guilty even years later. It influences negatively on their self-esteem, reduce their capacity for work and skills communication.

My clients who were "sacrifice" of car accident suffered from lack of belief in oneself, irrational fears about unpredictable dramatic events which can happen not only with them, but also with members of their family.

I come to conclusion that car accident in some cases provokes negative belief about oneself hidden in sub consciousness, exacerbates existing child trauma. That is the reason why even small road crash may evoke strong and long-term emotional reaction.

In my paper I would like to present psychological methods which I effectively use in order to help my clients to overcome the psychological trauma caused by a car accident. Among them is EMDR therapy - Eye Movement Desensitization and Reprocessing. I am going to show how I combine that psychological treatment with other approaches based on connection between mind and body.
\end{abstract}

Keywords: emotional trauma, post-traumatic stress disorders, car accident, EMDR treatment 